\title{
Body Mass Index: A Scientific Evidence-Based Inquiry
}

\author{
Dialma Rabelo Ricardo, Claudio Gil Soares de Araújo
}

Rio de Janeiro, RJ - Brazil

\begin{abstract}
Objective -To objectively and critically assess body mass index and to propose alternatives for relating body weight and height that are evidence-based and that eliminate or reduce the limitations of the body mass index.

Methods - To analyze the relations involving weight and height, we used 2 databases as follows: 1) children and adolescents from Brazil, the United States, and Switzerland; and 2) 538 university students. We performed mathematical simulations with height data ranging from 115 to $190 \mathrm{~cm}$ and weight data ranging from 25 to $105 \mathrm{~kg}$. We selected 3 methods to analyze the relation of weight and height as follows: body mass index - weight (kg)/height $\left(\mathrm{m}^{2}\right)$; reciprocal of the ponderal index - height $(\mathrm{cm}) /$ weight ${ }^{1 / 3}(\mathrm{~kg})$; and ectomorphy. Using the normal range from 20 to $25 \mathrm{~kg} / \mathrm{m}^{2}$ for the body mass index in the reference height of $170 \mathrm{~cm}$, we identified the corresponding ranges of 41 to $44 \mathrm{~cm} / \mathrm{kg}^{1 / 3}$ for the reciprocal of the ponderal index, and of 1.45 to 3.60 for ectomorphy.
\end{abstract}

Results - The mathematical simulations showed a strong association among the 3 methods with an absolute concordance to a height of $170 \mathrm{~cm}$, but with a tendency towards discrepancy in the normal ranges, which had alrea$d y$ been observed for the heights of 165 and $175 \mathrm{~cm}$. This made the direct convertibility between the indices unfeasible. The reciprocal of the ponderal index and ectomorphy with their cut points comprised a larger age range in children and adolescents and $a$ wider and more central range in the university students, both for the reported (current) and desired weights.

Conclusion - The reciprocal of the ponderal index and ectomorphyarestrongerandaremoremathematically logical than body mass index; in addition, they may be applied with the same cut points for normal from the age of $5 \frac{1}{2}$ years on.

Key words: body mass index, ectomorphy, reciprocal of the ponderal index

Universidade Gama Filho and Clinimex - Clínica de Medicina do Exercício Mailing address: Claudio GilS. Araújo-Clínica de Medicina doExercício Rua Siqueira Campos, 93/101 - 22031-070 - Rio de Janeiro, RJ, Brazil - E-mail: cgaraujo@iis.com.br English version by Stela Maris C. e Gandour
The human body has linear, area, and volume measurements. A tendency towards a natural proportionality in body measures exists, and it varies with sex and the growth and developmental degrees ${ }^{1}$. According to allometry, height and body weight are, respectively, measures of the linear and volume nature of an organism ${ }^{2}$. These 2 anthropometric variables, whose measures are simple and reliable, have been classically used to morphologically characterize an individual. In the XIX century, Quételet proposed a strategy to mathematically relate an individual's weight and height. According to a MEDLINE search, this strategy, which was later named body mass index ${ }^{3}$, has appeared in more than 6,000 articles since 1994, and it has scientific and epidemiological consistency. Different authors and international agencies ${ }^{4-7}$ have proposed normal ranges for the body mass index of adults, which allow the identification of undernourished, overweight, and obese individuals. The normal values in adolescents, children, and infants, however, are distinct and based on percentiles ${ }^{8-11}$.

Recently, the prevalence of overweight and obesity has increased in all countries worldwide; in the United States, the proportion of obese adults practically doubled, increasing from $12.8 \%$ between $1960-1962$ to $22.5 \%$ between 1988-1994 ${ }^{12}$. According to IBGE (Brazilian Institute of Geography and Statistics) data ${ }^{13}$, in Brazil, the number of obese males increased from 4.5 to $7 \%$ between the years 1989 and 1997 , showing that this is a problem not only in developed countries, but also in developing ones.

Overweight has been associated historically with chronic and degenerative diseases, such as ischemic heart disease ${ }^{7,14-16}$, systemic arterial hypertension ${ }^{17,18}$, dy slipidemia ${ }^{19,20}$, chronic obstructive pulmonary disea$\mathrm{se}^{21}$, gallbladder disease ${ }^{22}$, diabetes mellitus ${ }^{19}$, and some types of cancer ${ }^{23-28}$. Elevated values of body mass in dex have been associated with high rates of morbidity and mortality $7,15,29-32$.

Even though body mass index has been widely used in clinical practice, several theoretical restrictions to its use and its recommended normal ranges exist. Sexual and ethnic differences, and differences in the patterns of regular physical activity ${ }^{33-36}$, and consequently, in the level of adiposity, 
may contribute to some limitations of the body mass index. It is even possible that the passage of time, stressed by biological and even cultural factors, may interfere with the consistency of the body mass index. An example may be seen in the anthropometric data of famous women, such as female models ${ }^{37}$ or those participating in the Miss America Beauty Pageant ${ }^{38}$. Even though these women may socially be considered acceptable, a high prevalence of patterns corresponding to clinical undernourishment would be observed if the current criteria for body mass index were applied.

Therefore, it seems appropriate to critically review the use of the body mass index, especially in children and adolescents, and, if possible, to propose alternatives that provide simplicity associated with a greater mathematical and theoretical coherence.

The objective of this study was to compare 3 methods of presenting the weight and height relations for children, adolescents, and adults, assessing their consistency and mathematical formulation. We also aimed at identifying the respective normal ranges, determining in a satisfactory manner the individuals who fit those spectra of linearity considered normal. Our study comprised 3 independent studies designed to analyze the results obtained from the weight and height relations in different populations.

\section{Methods}

We selected the following 3 procedures to analyze the body weight/height relation: 1) the body mass index, in which the weight/height relation is mathematically defined by the following equation: weight $\left.(\mathrm{kg}) / \mathrm{height}^{2}(\mathrm{~m}) ; 2\right)$ the reciprocal of the ponderal index, also known as Sheldon's index ${ }^{39}$, which is calculated using the following equation: height $(\mathrm{cm}) /$ weight $^{1 / 3}(\mathrm{~kg})$. According to the allometric model, the latter relation has a stronger mathematical foundation, because weight is a variable of cubic dimensions and height is a variable of linear dimensions ${ }^{40}$; 3) the ectomorphy, the third component of the somatotype, represents the relative linearity of the individual ${ }^{41}$. In the $1960 \mathrm{~s}$, the anthropologist Barbara Heath and the Physical Education professor John E. Lindsay Carter ${ }^{42}$ proposed, based on the previous studies by Parnell, the Heath-Carter anthropometric somatotyping method to determine the somatotype. And even more important, they recognized the limitations inherent in the closed numerical scale, which had been originally proposed by Sheldon, and those authors began to accept an unlimited and open scale in only one direction. Later, Araújo ${ }^{43}$ stressed the theoretical inconsistency of the method of open scales in only one direction and showed with actual examples of obese individuals its practical limitations, especially in regard to ectomorphy. Therefore, occasional negative values obtained with the formulae of the components became accepted and no longer arbitrarily transformed into 0.1 .

The scale for measuring ectomorphy is nondimensional and of a continuous and intervallic nature. In practice, ectomorphy is determined on the basis of the reciprocal of the ponderal index using the linear equation: ectomorphy $=[2.42$ $\mathrm{x}\left((\right.$ height $\left.\left.(\mathrm{cm}) / 2.54) /(\text { weight }(\mathrm{kg}) / 0.4536)^{1 / 3}\right)-28.58\right]$. It is worth noting that the units were converted to $\mathrm{cm}$ and $\mathrm{kg}^{2,40}$. Even though the reciprocal of the ponderal index and ectomorphy represent basically the same information, ectomorphy is more frequently used and is one of the components of the somatotype, which is a very frequently used kinanthropometry technique. It allows a more global analysis of the body composition and physique of the individual when analyzed along with the 2 other components, endomorphy and mesomorphy.

The cut points were divided into 3 categories for all the selected methods: underweight, normal weight, and overweight (tab. I).

For body mass index, we used the limits recommended by the International Obesity Task Force (IOTF) ${ }^{4}$. Even though that institution considers as underweight a body mass index below $18.5 \mathrm{~kg} / \mathrm{m}^{2}$, we chose a higher cut point as reported by Wang et $\mathrm{al}^{6}$. Therefore, we considered values below $20 \mathrm{~kg} / \mathrm{m}^{2}$ as underweight, because no consensus in regard to lower cut points exists among the institutions and the specialists in the area. To define the cut points and the normal range for the reciprocal of the ponderal index and ectomorphy, we used the respective equivalent values of the normal body mass indices for a height of $170 \mathrm{~cm}$. We had already validated the referred cut points for the reciprocal of the ponderal index and ectomorphy in another population, and concluded that the discrimination power of both was similar to that originally proposed for the body mass index ${ }^{44}$.

In study 1 , we analyzed the weight/height relations in children and adolescents with ages ranging from 2 to 12 years in 3 different countries (Brazil, the United States, and Switzerland). Data regarding Brazil were collected in the cross-sectional study by Marcondes et $\mathrm{al}^{45}$, who assessed 9,258 children ( 4,603 boys and 4,655 girls) in the city of Santo André, in the state of São Paulo. These children belonged to a social class considered normal in regard to life conditions and from the nutritional point of view. Data on these children were grouped in tables with 5 columns, and the middle column corresponded to the medium value. To make the 3 databases uniform, we considered this medium value equivalent to the median value, ie, the $50^{\text {th }}$ percentile.

\begin{tabular}{|lc|}
\hline \multicolumn{2}{|c|}{ Table I-Cut points for the weight and height relations } \\
\hline Method & Cut points \\
\hline BMI $\left(\mathrm{kg} / \mathrm{m}^{2}\right)$ & $<20$ - underweight \\
& 20 a 25 - normal \\
& $>25$ - overweight \\
& $>44$ - underweight \\
RIP $\left(\mathrm{cm} / \mathrm{kg}^{1 / 3}\right)$ & 41 a 44 - normal \\
& $<41$ - overweight \\
& $>3,6$ - underweight \\
ECTO (nondimensional) & 1,45 a 3,6 - normal \\
& $<1,45$ - overweight \\
& \\
BMI- body mass index; RPI - reciprocal of the ponderal index; ECTO - & \\
ectomorphy & \\
\hline
\end{tabular}


The values of weight and height regarding the population sample of the United States were collected in a publication of the National Center for Health Statistics (NCHS) ${ }^{46}$ with a total of 20,000 individuals of both sexes and ages ranging from 2 to 18 years during the period from 1963 to 1975.

We also analyzed the anthropometric data from the northwestern region of Switzerland (Basel) found in a study of 4,300 individuals with an equal proportion of sexes, and ages ranging from 2 to 17 years, carried out from 1956 to $1957^{46}$.In our study, we only used data relating to the age bracket from 2 to 12 years, minimizing the occasional influences of processes of biological maturation with distinct rhythms.

Once data were arranged in a table, we established the cut points - underweight, normal weight, and overweight proposed for each method (body mass index, reciprocal of the ponderal index, and ectomorphy). If the methods applied equally well for the analysis of the weight/height ratio of children and adolescents of both sexes and all ages, the individuals in the $50^{\text {th }}$ percentile for weight and height would be within the normal range.

To check the consistency of the indicators to foretell the normal range in adults, which comprised study 2 , we performed a mathematical simulation using data of heights between 115 and $190 \mathrm{~cm}$ (at every $5 \mathrm{~cm}$ ) and of weights between 25 and $105 \mathrm{~kg}$ (at every $2.5 \mathrm{~kg}$ ). This way, we obtained a total of 528 weight/height ratios for each of the 3 methods. In addition, data for 3 different heights were separated - 145, 160 , and $170 \mathrm{~cm}$ - in the following body weight ranges: between 25 and $60 \mathrm{~kg}$, between 40 and $85 \mathrm{~kg}$, and between 45 and $90 \mathrm{~kg}$, respectively. The height $145 \mathrm{~cm}$ was chosen because, according to Marcondes (1978), it represents the approximate value of a Brazilian peripuberal adolescent. The remaining heights selected, 160 and $170 \mathrm{~cm}$, represent, respectively, a typical Brazilian female and male ${ }^{13}$. We also determined the linear regressions between the body mass index and ectomorphy for the 3 above-mentioned heights in at least 10 distinct body weights.

In the composition of study 3 , we used data of the heights and current and desired weights of 538 (331 females and 207 males) students of the Universidade Gama Filho ${ }^{47}$, and calculated the weight/height ratios according to the 3 methods selected. After that, we demarcated the normal ranges for the predictors of weight/height relations according to previous studies.

The individuals were arranged in percentiles (from the $1^{\text {st }}$ to the $\left.99^{\text {th }}\right)$ from the lightest individual to the heaviest individual according to the results of the weight/height ratios. We could assess the strength of each method according to the number of individuals within the normal range.

In a subsequent analysis, we checked the validity of the methods to estimate the normal range for body weight in relation to height, independent of sex, comparing the weight/height relations reported by the interviewees using the desired body weight.

In this specific study, we performed a descriptive analysis of the scores, and we used the Pearson linear correlation coefficient to assess the degree of association between the indicators.

\section{Results}

Study 1 - Analyzing the weight/height relations in children, we observed that none of the methods studied (body mass index, reciprocal of the ponderal index, and ectomorphy) had a satisfactory consistency to safely identify the normal ranges for the age bracket from 2 to $5 \frac{1}{2}$ years in the 3 databases assessed. However, from that age to 12 years, the reciprocal of the ponderal index and ectomorphy almost correctly identified children in the $50^{\text {th }}$ percentiles for height and weight in both sexes. We could also observe that the body mass index did not reflect the relative linearity for any age or sex in this population when the $50^{\text {th }}$ percentile was considered for weight and height. This can be seen in tables II and III in which the normal range is represented as a gray background.

Study 2 - The mathematical simulations performed in the $2^{\text {nd }}$ study showed that the 3 methods used to analyze the weight/height relation are strongly associated $(r>0.97$; $\mathrm{P}<0.001$ ), especially when limited weight and height ranges are considered with an absolute coincidence at the height of $170 \mathrm{~cm}$. However, we observed a tendency towards discrepancy in the normal ranges in the 3 me thods, and this tendency could already be observed for the height values of 165 and $175 \mathrm{~cm}$ (not shown in the table), and it was even more marked in extreme height values, such as $145 \mathrm{~cm}$ (tab. IV).

Even though a strong association exists among the 3 methods in relating weight and height, the coefficients of regression tend to be distinct, because the predictive equations diverge in regard to the constant and the correlation coefficient (coefficient $\mathrm{X}$ ), therefore, hindering the direct convertibility between the methods. This fact may be seen in the simulations of height $(145,160$, and $170 \mathrm{~cm})$, in which we observed that the linear equation of prediction proposed for a certain height could not be used for another height, as shown in table V.

For example, the ectomorphy of a $160-\mathrm{cm}$-tall individual weighing $50 \mathrm{~kg}$ would be 3.21 . On the other hand, if we used the proposed equation for the height of $170 \mathrm{~cm}$, a mistake would occur in that prediction, as exemplified below: $\mathrm{BMI}=-2.168 . \mathrm{X}+28.3$ (where $\mathrm{X}=\mathrm{ECTO}$ ); $\mathrm{BMI}=-2.168$. $3.21+28.3$, where the body mass index (predicted through the equation) $=21.34 \mathrm{~kg} / \mathrm{m}^{2}$ and the actual body mass index $=19.53\left[\left(\right.\right.$ weight $(\mathrm{kg}) /$ height $\left.^{2}(\mathrm{~m})\right]$.

Study 3 -The 2 predictors of the weight/height relation presented in this study found a greater number of individuals within the normal range proposed for the referred methods when the weights and heights reported by the university students were considered. This phenomenon could be better observed when the results of the weight/height relations were transformed into percentiles, where the reciprocal of the ponderal index and the ectomorphy discriminated from the $30^{\text {th }}$ to the $90^{\text {th }}$ percentiles and from the $20^{\text {th }}$ to the $95^{\text {th }}$ percentiles formales and females, respectively. This was different from the finding when we used body mass index, in which the normal range encompassed only 


\begin{tabular}{|c|c|c|c|c|c|c|c|c|c|}
\hline \multirow[b]{2}{*}{ Age } & \multicolumn{3}{|c|}{ Brazil } & \multicolumn{3}{|c|}{ United States } & \multicolumn{3}{|c|}{ Switzerland } \\
\hline & $\begin{array}{c}\text { BMI } \\
\left(\mathrm{kg} / \mathrm{m}^{2}\right)\end{array}$ & $\begin{array}{c}\mathrm{RPI} \\
\left(\mathrm{cm} / \mathrm{kg}^{1 / 3}\right)\end{array}$ & ЕСТО & $\begin{array}{c}\text { BMI } \\
\left(\mathrm{kg} / \mathrm{m}^{2}\right)\end{array}$ & 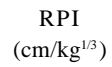 & ЕСТО & $\begin{array}{c}\text { BMI } \\
\left(\mathrm{kg} / \mathrm{m}^{2}\right)\end{array}$ & 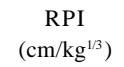 & ЕСТO \\
\hline 2 & 17.2 & 37.0 & -1.49 & 16.4 & 37.6 & -1.08 & 16.4 & 37.6 & -1.06 \\
\hline 2.5 & 16.9 & 37.8 & -0.93 & 16.5 & 37.9 & -0.80 & 15.8 & 38.8 & -0.17 \\
\hline 3 & 16.5 & 38.6 & -0.30 & 16.2 & 38.8 & -0.17 & 15.7 & 39.4 & 0.26 \\
\hline 3.5 & 16.4 & 39.1 & 0.05 & 16.0 & 39.6 & 0.40 & 15.7 & 39.9 & 0.66 \\
\hline 4 & 16.3 & 39.6 & 0.39 & 15.8 & 40.3 & 0.90 & 15.6 & 40.5 & 1.06 \\
\hline 4.5 & 16.3 & 40.0 & 0.68 & 15.6 & 40.9 & 1.37 & 16.5 & 39.8 & 0.52 \\
\hline 5 & 16.3 & 40.3 & 0.94 & 15.5 & 41.4 & 1.75 & 16.5 & 40.2 & 0.85 \\
\hline 5.5 & 16.1 & 41.0 & 1.44 & 15.4 & 41.9 & 2.09 & 15.6 & 41.8 & 2.00 \\
\hline 6 & 16.2 & 41.3 & 1.65 & 15.3 & 42.3 & 2.38 & 15.5 & 42.2 & 2.33 \\
\hline 6.5 & 16.3 & 41.6 & 1.85 & 15.4 & 42.6 & 2.63 & 15.5 & 42.6 & 2.59 \\
\hline 7 & 16.4 & 41.8 & 2.05 & 15.4 & 42.9 & 2.82 & 15.5 & 42.9 & 2.84 \\
\hline 7.5 & 16.4 & 42.1 & 2.27 & 15.5 & 43.1 & 2.98 & 15.5 & 43.2 & 3.06 \\
\hline 8 & 16.4 & 42.5 & 2.52 & 15.7 & 43.3 & 3.09 & 15.4 & 43.6 & 3.34 \\
\hline 8.5 & 16.7 & 42.5 & 2.54 & 15.9 & 43.4 & 3.18 & 15.5 & 43.9 & 3.55 \\
\hline 9 & 16.6 & 42.9 & 2.82 & 16.1 & 43.5 & 3.24 & 15.5 & 44.2 & 3.75 \\
\hline 9.5 & 16.8 & 43.0 & 2.87 & 16.4 & 43.5 & 3.27 & 15.5 & 44.4 & 3.93 \\
\hline 10 & 17.0 & 43.0 & 2.91 & 16.6 & 43.6 & 3.31 & 15.9 & 44.4 & 3.89 \\
\hline 10.5 & 17.2 & 43.0 & 2.91 & 16.9 & 43.6 & 3.34 & 16.5 & 44.0 & 3.61 \\
\hline 11 & 17.6 & 42.9 & 2.83 & 17.2 & 43.7 & 3.40 & 17.2 & 43.6 & 3.36 \\
\hline 11.5 & 18.2 & 42.7 & 2.66 & 17.5 & 43.8 & 3.45 & 17.8 & 43.3 & 3.12 \\
\hline 12 & 18.7 & 42.5 & 2.55 & 17.8 & 43.9 & 3.52 & 18.3 & 43.2 & 3.02 \\
\hline
\end{tabular}

\begin{tabular}{|c|c|c|c|c|c|c|c|c|c|}
\hline \multirow[b]{3}{*}{ Age } & \multicolumn{9}{|c|}{ Table III - The $50^{\text {th }}$ percentile for weight and height - girls } \\
\hline & \multicolumn{3}{|c|}{ Brazil } & \multicolumn{3}{|c|}{ United States } & \multicolumn{3}{|c|}{ Switzerland } \\
\hline & $\begin{array}{c}\text { BMI } \\
\left(\mathrm{kg} / \mathrm{m}^{2}\right)\end{array}$ & $\begin{array}{c}\mathrm{RPI} \\
\left(\mathrm{cm} / \mathrm{kg}^{1 / 3}\right)\end{array}$ & ЕСТO & $\begin{array}{c}\text { BMI } \\
\left(\mathrm{kg} / \mathrm{m}^{2}\right)\end{array}$ & $\begin{array}{c}\text { RPI } \\
\left(\mathrm{cm} / \mathrm{kg}^{1 / 3}\right)\end{array}$ & ЕСТO & $\begin{array}{c}\text { BMI } \\
\left(\mathrm{kg} / \mathrm{m}^{2}\right)\end{array}$ & $\begin{array}{c}\text { RPI } \\
\left(\mathrm{cm} / \mathrm{kg}^{1 / 3}\right)\end{array}$ & ECTO \\
\hline 2 & 16.9 & 37.0 & -1.46 & 15.7 & 38.1 & -0.67 & 15.9 & 37.9 & -0.84 \\
\hline 2.5 & 16.5 & 38.1 & -0.71 & 16.1 & 38.2 & -0.58 & 15.8 & 38.6 & -0.32 \\
\hline 3 & 16.3 & 38.8 & -0.18 & 15.9 & 39.0 & -0.07 & 15.8 & 39.2 & 0.13 \\
\hline 3.5 & 16.3 & 39.2 & 0.10 & 15.7 & 39.6 & 0.43 & 15.7 & 39.8 & 0.55 \\
\hline 4 & 16.0 & 40.0 & 0.69 & 15.5 & 40.4 & 0.96 & 15.6 & 40.3 & 0.96 \\
\hline 4.5 & 15.9 & 40.4 & 0.99 & 15.2 & 41.0 & 1.43 & 15.5 & 40.9 & 1.37 \\
\hline 5 & 15.9 & 40.8 & 1.28 & 15.0 & 41.6 & 1.89 & 15.3 & 41.4 & 1.76 \\
\hline 5.5 & 15.9 & 41.2 & 1.56 & 14.9 & 42.2 & 2.28 & 15.3 & 41.9 & 2.10 \\
\hline 6 & 16.2 & 41.2 & 1.56 & 14.9 & 42.6 & 2.58 & 15.3 & 42.3 & 2.37 \\
\hline 6.5 & 16.2 & 41.5 & 1.83 & 14.2 & 44.0 & 3.62 & 15.3 & 42.7 & 2.66 \\
\hline 7 & 16.2 & 41.9 & 2.10 & 15.0 & 43.1 & 3.00 & 17.5 & 41.2 & 1.59 \\
\hline 7.5 & 16.2 & 42.3 & 2.36 & 15.3 & 43.3 & 3.09 & 16.0 & 42.8 & 2.73 \\
\hline 8 & 16.1 & 42.6 & 2.63 & 15.5 & 43.3 & 3.13 & 16.2 & 42.9 & 2.82 \\
\hline 8.5 & 16.4 & 42.7 & 2.65 & 15.9 & 43.3 & 3.14 & 16.2 & 43.2 & 3.03 \\
\hline 9 & 16.4 & 43.0 & 2.90 & 16.3 & 43.3 & 3.12 & 16.2 & 43.5 & 3.23 \\
\hline 9.5 & 16.4 & 43.3 & 3.12 & 16.7 & 43.3 & 3.11 & 16.4 & 43.6 & 3.32 \\
\hline 10 & 16.7 & 43.2 & 3.07 & 17.0 & 43.3 & 3.13 & 16.7 & 43.5 & 3.29 \\
\hline 10.5 & 16.9 & 43.4 & 3.18 & 17.3 & 43.4 & 3.17 & 17.0 & 43.5 & 3.26 \\
\hline 11 & 17.2 & 43.4 & 3.21 & 17.6 & 43.5 & 3.25 & 17.3 & 43.4 & 3.21 \\
\hline 11.5 & 17.7 & 43.3 & 3.12 & 17.9 & 43.6 & 3.35 & 17.6 & 43.5 & 3.29 \\
\hline 12 & 18.5 & 42.9 & 2.89 & 18.1 & 43.7 & 3.45 & 17.7 & 43.8 & 3.48 \\
\hline
\end{tabular}

from the $5^{\text {th }}$ to the $65^{\text {th }}$ percentiles and from the $30^{\text {th }}$ to the $85^{\text {th }}$ percentiles, respectively for university males and females. The reciprocal of the ponderal index and the ectomorphy encompassed a more central and wider range for the university students of both sexes than the body mass index did (tabs. VI and VII).

For an index considered ideal by the university students, ie, the desired weight (the amount the individual would like to weigh) and the reported height (current), data strengthen even more the validity of the measures and the normal ranges of the reciprocal of the ponderal index and of ectomorphy as compared with body mass index, once again encompassing a wider and more central range of the sample. Another interesting fact was the asymmetry found in the desired body mass index for males and females, which ranged from lower values in males to higher values in females. These results enabled a crossed validation of the indicators here studied, because the desired indices represent the li- 


\begin{tabular}{|c|c|c|c|c|c|c|c|c|}
\hline \multicolumn{3}{|c|}{ Height $=145 \mathrm{~cm}^{*}$} & \multicolumn{3}{|c|}{ Height $=160 \mathrm{~cm}^{*}$} & \multicolumn{3}{|c|}{ Height $=170 \mathrm{~cm}^{*}$} \\
\hline $\begin{array}{l}\text { Peso } \\
(\mathrm{kg})\end{array}$ & $\begin{array}{c}\text { BMI } \\
\left(\mathrm{kg} / \mathrm{m}^{2}\right)\end{array}$ & ECTO & $\begin{array}{r}\text { Peso } \\
(\mathrm{kg})\end{array}$ & $\begin{array}{c}\mathrm{BMI} \\
\left(\mathrm{kg} / \mathrm{m}^{2}\right)\end{array}$ & ЕСТО & $\begin{array}{l}\text { Peso } \\
(\mathrm{kg})\end{array}$ & $\begin{array}{c}\text { BMI } \\
\left(\mathrm{kg} / \mathrm{m}^{2}\right)\end{array}$ & ЕСТO \\
\hline 25 & 11.9 & 7.72 & 40 & 15.6 & 5.67 & 45 & 15.6 & 6.41 \\
\hline 27.5 & 13.1 & 6.59 & 42.5 & 16.6 & 4.98 & 47.5 & 16.4 & 5.78 \\
\hline 30 & 14.3 & 5.58 & 45 & 17.6 & 4.35 & 50 & 17.3 & 5.20 \\
\hline 32,5 & 15.5 & 4.68 & 47.5 & 18.6 & 3.76 & 52.5 & 18.2 & 4.66 \\
\hline 35 & 16.6 & 3.87 & 50 & 19.5 & 3.21 & 55 & 19.0 & 4.14 \\
\hline 37.5 & 17.8 & 3.13 & 52.5 & 20.5 & 2.70 & 57.5 & 19.9 & 3.66 \\
\hline 40 & 19.0 & 2.46 & 55 & 21.5 & 2.22 & 60 & 20.8 & 3.21 \\
\hline 42.5 & 20.2 & 1.84 & 57.5 & 22.5 & 1.77 & 62.5 & 21.6 & 2.78 \\
\hline 45 & 21.4 & 1.26 & 60 & 23.4 & 1.34 & 65 & 22.5 & 2.37 \\
\hline 47.5 & 22.6 & 0.73 & 62.5 & 24.4 & 0.93 & 67.5 & 23.4 & 1.98 \\
\hline 50 & 23.8 & 0.23 & 65 & 25.4 & 0.55 & 70 & 24.2 & 1.62 \\
\hline 52.5 & 25.0 & -0.23 & 67.5 & 26.4 & 0.19 & 72.5 & 25.1 & 1.27 \\
\hline 55 & 26.2 & -0.67 & 70 & 27.3 & -0.16 & 75 & 26.0 & 0.93 \\
\hline 57.5 & 27.3 & -1.08 & 72.5 & 28.3 & -0.49 & 77.5 & 26.8 & 0.61 \\
\hline 60 & 28.5 & -1.47 & 75 & 29.3 & -0.81 & 80 & 27.7 & 0.30 \\
\hline
\end{tabular}

\begin{tabular}{|lccc|}
\hline \multicolumn{4}{|c|}{ Table V - Equations of prediction } \\
\hline Simulated heights & $145 \mathrm{~cm}$ & $160 \mathrm{~cm}$ & $170 \mathrm{~cm}$ \\
\hline \multirow{2}{*}{ Equation } & $\mathrm{Y}=-1.822$ & $\mathrm{Y}=-2.324$ & $\mathrm{Y}=-2.168$ \\
& $\mathrm{X}+24.42$ & $\mathrm{X}+27.36$ & $\mathrm{X}+28.29$ \\
\hline \multicolumn{4}{|c|}{$\mathrm{Y}=\mathrm{BMI} ; \mathrm{X}=$ ECTO or RPI values } \\
\hline
\end{tabular}

nearity that the university students would like to have, ie, an ideal weight for a certain height. In this specific case, the reciprocal of the ponderal index and ectomorphy showed a greater discriminating power than that of body mass index.

As suggested by the mathematical simulation in study 2 , the relation among body mass index, the ectomorphy, and the reciprocal of the ponderal index $(\mathrm{r}=-0.89 ; \mathrm{P}<0.001)$, despite its significance, has lower correlation coefficients, showing that, even though for the fixed height of $170 \mathrm{~cm}$ that relation is almost perfect, for real data in which height varies, a significant loss occurs in the association.

\section{Discussion}

Obesity in childhood is a public health problem, whose importance has progressively increased in the last few years ${ }^{8,9,29,48}$. Evidence suggests that the chance of an obese child or adolescent becoming an obese adult is approximately $30 \% 49$. On the other hand, obesity in adulthood is associated with chronic and degenerative diseases, morbidity, and mortality ${ }^{14,50}$. However, estimation of the prevalence of obesity in childhood with a safe, reliable, and valid indicator using criteria similar to those used for adults had not yet been possible.

The methods used to diagnose overweight and obesity, and to determine the normal ranges and underweight in this population are numerous. The skinfold measure, mainly the triceps skinfold measure, has been largely used to estimate overweight and obesity in children and adolescents ${ }^{49,51}$ with a high association with the direct measures of adiposity, especially between the ages of 10 and 15 years ${ }^{52}$. Its application, however, is limited, because it requires highly experienced evaluators, and also because of the existence of the recognized intra- and interevaluator variability of the measures ${ }^{53}$. Other anthropometric measures have also been used, among which we can highlight the following: the circumference, relative weight, weight for age, somatotype, and finally the weight and height relations, among which we stress body mass index.

The results of study 1 confirm the unfeasibility of the application of the normality criteria of the body mass index used for adults as an indicator of overweight and obesity for children, because it did not reflect the relative linearity of that population. In contrast, the reciprocal of the ponderal index and the ectomorphy using normal ranges derived from the body mass index for the standard height of $170 \mathrm{~cm}$ could identify individuals in a spectrum of linearity considered normal $\left(50^{\text {th }}\right.$ percentile of weight and height $)$ independent of sex and between the ages of 5.5 and 12 years in 3 databases of different regions of the planet. The only exception to this rule was observed at one single age in the database of the Swiss children, probably related to the influence of the early pubescent growth spurt in part of the sample or to another unidentified sample characteristic. This showed a greater independence of these predictors in regard to the intervening variables, which are inherent in the weight and height relations, such as age, sexual maturation, ethnicity, sexual dimorphism, and height itself.

Height has a relevant influence on the estimation of obesity by these indicators ${ }^{34,54,55}$, drastically interfering with their results, mainly in children, in whom they remain in constant change up to adulthood, in addition to having a strict correlation with body weight ${ }^{56}$. Based on this assum- 


\begin{tabular}{|c|c|c|c|c|c|c|}
\hline \multicolumn{7}{|c|}{ Table VI - Weight/height relations - male university students } \\
\hline Percentil & ЕСТО & $\begin{array}{c}\mathrm{RPI} \\
\left(\mathrm{kg} / \mathrm{cm}^{1 / 3}\right)\end{array}$ & $\begin{array}{c}\text { BMI } \\
\left(\mathrm{kg} / \mathrm{m}^{2}\right)\end{array}$ & ECTOd* & $\begin{array}{c}\mathrm{RPId}^{*} \\
\left(\mathrm{~kg} / \mathrm{cm}^{1 / 3}\right)\end{array}$ & $\begin{array}{l}\text { BMId* } \\
\left(\mathrm{kg} / \mathrm{m}^{2}\right)\end{array}$ \\
\hline 1 & -2.31 & 35,9 & 18.2 & -0.93 & 37.8 & 19.6 \\
\hline 2 & -0.28 & 38.7 & 19.0 & -0.10 & 38.9 & 20.2 \\
\hline 3 & -0.20 & 38.8 & 19.8 & 0.52 & 39.8 & 20.3 \\
\hline 5 & 0.00 & 39.0 & 20.2 & 0.80 & 40.1 & 20.8 \\
\hline 10 & 0.76 & 40.1 & 21.0 & 1.30 & 40.8 & 21.8 \\
\hline 15 & 0.93 & 40.3 & 21.3 & 1.46 & 41.0 & 22.2 \\
\hline 20 & 1.11 & 40.6 & 22.1 & 1.59 & 41.2 & 22.6 \\
\hline 25 & 1.39 & 40.9 & 22.5 & 1.69 & 41.4 & 22.8 \\
\hline 30 & 1.57 & 41.2 & 22.8 & 1.86 & 41.6 & 23.1 \\
\hline 35 & 1.69 & 41.3 & 23.3 & 1.97 & 41.7 & 23.2 \\
\hline 40 & 1.83 & 41.5 & 23.5 & 2.02 & 41.8 & 23.4 \\
\hline 45 & 1.96 & 41.7 & 23.7 & 2.13 & 42.0 & 23.5 \\
\hline 50 & 2.05 & 41.8 & 24.1 & 2.22 & 42.1 & 23.7 \\
\hline 55 & 2.15 & 42.0 & 24.4 & 2.29 & 42.2 & 23.9 \\
\hline 60 & 2.32 & 42.2 & 24.6 & 2.34 & 42.2 & 24.1 \\
\hline 65 & 2.48 & 42.4 & 24.8 & 2.42 & 42.4 & 24.2 \\
\hline 70 & 2.62 & 42.6 & 25.2 & 2.51 & 42.5 & 24.6 \\
\hline 75 & 2.92 & 43.0 & 25.6 & 2.69 & 42.7 & 24.8 \\
\hline 80 & 3.04 & 43.2 & 26.0 & 2.91 & 43.0 & 25.0 \\
\hline 85 & 3.29 & 43.5 & 26.7 & 3.05 & 43.2 & 25.5 \\
\hline 90 & 3.60 & 44.0 & 27.8 & 3.29 & 43.5 & 26.0 \\
\hline 95 & 4.24 & 44.8 & 29.3 & 3.60 & 44.0 & 26.8 \\
\hline 97 & 4.51 & 45.2 & 30.2 & 3.78 & 44.2 & 27.3 \\
\hline 98 & 4.56 & 45.3 & 31.1 & 3.80 & 44.2 & 28.3 \\
\hline 99 & 4.67 & 45.4 & 35.1 & 4.28 & 44.9 & 32.4 \\
\hline
\end{tabular}

ption, a valid and reliable indicator that may safely reflect overweight and obesity in addition to expressing the proper linearity for a child should have a high correlation with body weight, but a minimum association with height ${ }^{57,58}$. Unfortunately, this statement does not apply to body mass index, because, according to Garn et al ${ }^{59}$, body mass index had a strong relation to height in children $(\mathrm{r}=0.30)$ when an expressive number was considered $(n=40,000)$. Garn ${ }^{60}$ confirmed the influence of height on body mass index and even added that the divisor of the equation (weight/height ${ }^{2}$ ) was originally squared in an attempt to correct this fact. Bellizzi and Dietz ${ }^{34}$, reported that even though body mass index had a high correlation with the measures of body density, it was not a perfect indicator for children due to its association with height. Therefore, we infer that body mass index should only be used with criteria adequate for this age bracket.

Another important question relates to the mathematical foundation of body mass index originally proposed by the Belgian astronomer and mathematician Lamber Adolphe Jacques Quételet (1769-1874) ${ }^{40}$, according to whom, that index would be provided by dividing weight $(\mathrm{kg})$ by height squared. According to allometry, 2 variables grow at different rates, both in structure and function. In this model, mass has a volumetric proportion, and, therefore, should be cubed; height, on the other hand, has a linear dimension and should be raised to the power of $1^{2,40}$. Both the reciprocal of the ponderal index and the ectomorphy respect this relation of dimension; therefore, they have a better mathematical logic from the biological system point of view.

Therefore, the reciprocal of the ponderal index and ec- tomorphy have greater accuracy and strength for identifying those individuals who fit a normal standard of weight for a certain height. This is observed only from the age of 5.5 years on, because none of the methods relating weight and height managed to reflect the adequate linearity for the age between 2 and 5.5 years. This may be due to a question related to the complex disproportion of the child as compared with the adult.

A relevant fact to be discussed, specifically in study 1, regards the cut points proposed for the different methodsfor estimating the nutritional status of a child or adolescent, and upon which the international scientific community has not yet agreed ${ }^{9,51,34}$. Recently, Cole et al ${ }^{10}$ have proposed for children and adolescents a cut point for body mass index in percentiles based on the cut points used for 18year-old adults ( 25 and $30 \mathrm{~kg} / \mathrm{m}^{2}$, respectively for overweight and obesity). In most studies considering body mass index in children and adolescents, the percentile is the measure of dispersion most used to classify the in dividuals, a percentile $>85$ being used to identify overweight and a percentile $>95$ to indicate obesity ${ }^{61,62}$. However, these cut points are arbitrary ${ }^{8}$, because we consider that 5 and $15 \%$ of the population are, respectively, obese and overweight; sometimes, these numbers do not represent the sample universe ${ }^{52}$.

Nevertheless, we need strategies that may be used to compare the different existing databases and that may serve as a reference for comparisons between the linearity found in children and that of the parents. Body mass index seems not to serve this finality, but the reciprocal of the ponderal 


\begin{tabular}{|c|c|c|c|c|c|c|}
\hline Percentile & ECTO & $\begin{array}{c}\mathrm{RPI} \\
\left(\mathrm{kg} / \mathrm{cm}^{1 / 3}\right)\end{array}$ & $\begin{array}{c}\text { BMI } \\
\left(\mathrm{kg} / \mathrm{m}^{2}\right)\end{array}$ & ECTOd* & $\begin{array}{c}\mathrm{RPId}^{*} \\
\left(\mathrm{~kg} / \mathrm{cm}^{1 / 3}\right)\end{array}$ & $\begin{array}{l}\text { BMId* } \\
\left(\mathrm{kg} / \mathrm{m}^{2}\right)\end{array}$ \\
\hline 1 & -1.10 & 37.5 & 17.4 & 0.92 & 40.3 & 17.6 \\
\hline 2 & -0.66 & 38.1 & 17.8 & 1.31 & 40.8 & 17.7 \\
\hline 3 & -0.36 & 38.5 & 17.9 & 1.41 & 41.0 & 17.9 \\
\hline 5 & 0.23 & 39.4 & 18.2 & 1.60 & 41.2 & 18.3 \\
\hline 10 & 0.73 & 40.0 & 18.8 & 1.84 & 41.5 & 18.7 \\
\hline 15 & 1.28 & 40.8 & 19.1 & 2.21 & 42.1 & 19.0 \\
\hline 20 & 1.46 & 41.0 & 19.3 & 2.27 & 42.1 & 19.2 \\
\hline 25 & 1.82 & 41.5 & 19.6 & 2.48 & 42.4 & 19.3 \\
\hline 30 & 2.02 & 41.8 & 20.1 & 2.67 & 42.7 & 19.5 \\
\hline 35 & 2.09 & 41.9 & 20.3 & 2.81 & 42.9 & 19.7 \\
\hline 40 & 2.27 & 42.1 & 20.5 & 2.83 & 42.9 & 19.9 \\
\hline 45 & 2.42 & 42.3 & 20.8 & 3.00 & 43.1 & 20.0 \\
\hline 50 & 2.62 & 42.6 & 21.1 & 3.18 & 43.4 & 20.2 \\
\hline 55 & 2.81 & 42.9 & 21.5 & 3.19 & 43.4 & 20.3 \\
\hline 60 & 2.99 & 43.1 & 21.7 & 3.21 & 43.4 & 20.5 \\
\hline 65 & 3.13 & 43.3 & 22.1 & 3.38 & 43.7 & 20.7 \\
\hline 70 & 3.26 & 43.5 & 22.5 & 3.47 & 43.8 & 20.9 \\
\hline 75 & 3.40 & 43.7 & 22.7 & 3.59 & 43.9 & 21.1 \\
\hline 80 & 3.57 & 43.9 & 23.3 & 3.77 & 44.2 & 21.5 \\
\hline 85 & 3.76 & 44.2 & 24.1 & 3.85 & 44.3 & 21.9 \\
\hline 90 & 3.97 & 44.5 & 25.2 & 4.14 & 44.7 & 22.3 \\
\hline 95 & 4.34 & 45.0 & 26.7 & 4.37 & 45.0 & 23.1 \\
\hline 97 & 4.59 & 45.3 & 27.8 & 4.72 & 45.5 & 23.4 \\
\hline 98 & 4.83 & 45.6 & 29.0 & 4.80 & 45.6 & 23.9 \\
\hline 99 & 5.10 & 46.0 & 31.4 & 5.25 & 46.2 & 24.5 \\
\hline
\end{tabular}

index and the ectomorphy allow that, from the age of 5.5 years on, the same cut points of adults may be used regardless of the sex.

In adults, we observed that the results of study 2 confirmed those of the study by Lee et al ${ }^{58}$ who reported that the weight and height relations strongly correlate with height for values below $150 \mathrm{~cm}$ and above $190 \mathrm{~cm}$. These relations interfered in a relevant manner with the results of those indicators, even though those authors did not analyze the reciprocal of the ponderal index and ectomorphy. This confirmed the discrepancy found in the correlation coefficients and in the constant of the linear equations, when, in the 3 methods adopted, height separated out at $170 \mathrm{~cm}$.

The results found in study 3 showed that the reciprocal of the ponderal index and ectomorphy were stronger than body mass index in university students because those indices identified a greater range of normal-weight individuals in a given height both for the reported and desired weight and height relations. The cut points proposed for body mass index should be reviewed for an adult population, because, as observed in the database analyzed, this method indicated that $35 \%$ of the male university students were overweight and, therefore, would be at a higher risk for morbidity and mortality. This seems not to correspond to reality, because, according to data reported by the IBGE ${ }^{13}$, Brazil has $22 \%$ of overweight males in a wider range of age and socioeconomic conditions.

The limitations of body mass index as an instrument for identifying overweight and obesity in children, adoles- cents, adults, and the elderly are widely documented. Chart Ibriefly shows some relevant factors that interfere with the validity of body mass index.

The present study confirms some previous criticisms in regard to body mass index and proposes other strategies to assess the relative linearity and the nutritional status in distinct phases of life. The reciprocal of the ponderal index and ectomorphy also have limitations inherent in the indices that relate weight and height. They, however, were stronger and had a better mathematical foundation, in addition to having more adequate cut points, allowing, therefore, greater control upon some intervening variables.

In conclusion, based on our data, we confirm the limitations of body mass index, not only because it does not reflect body composition, but it also has intrinsic mathematical limitations that become more evident in the extremities of the height scale. Even though widely used in clinical practice and in studies of epidemiological characteristics, body mass index should be cautiously used even as an instrument of obesity and overweight screening, especially in children and adolescents, in whom other cut points are mandatory.

The reciprocal of the ponderal index and ectomorphy have better mathematical logic and greater consistency. Therefore, they undergo a smaller influence of extreme height data, and can be applied to adults and children older than 5 years and of both sexes. Likewise, the recommended cut points for the normal ranges of these methods are valid for a university population, especially when the desired 


\begin{tabular}{|c|c|c|}
\hline \multicolumn{3}{|c|}{ Chart I - Factors affecting the validity of the body mass index } \\
\hline Phases of life & Limitations & Authors \\
\hline Childhood and adolescence & $\begin{array}{l}\text { - Weight and height grow at distinct proportions throughout life } \\
\text { - Growth differences in regard to the maturation process } \\
\text { (ex. menarcheal age and the peak height velocity time) } \\
\text { - Influence of height } \\
\text { - Aroportionality: trunk and lower limb relations } \\
\text { Age, sexual dimorphism, ethnicity, and social class }\end{array}$ & $\begin{array}{l}\text { Sinclair }{ }^{1} \\
\text { Daniels et al }{ }^{63} \\
\text { Michielutte et al } \\
\text { Malina et al }{ }^{57} \\
\text { Gallagher et al }{ }^{33} \\
\text { Bellizzi et al }{ }^{34}\end{array}$ \\
\hline Adults & $\begin{array}{l}\text { - Correlation with height, which, despite being low, is still significant } \\
\text { - High lean mass } \\
\text { - Proportionality: trunk and lower limb relations } \\
\text { - High specificity and low and variable sensitivity } \\
\text { - Reflects neither the body fat nor its distribution }\end{array}$ & $\begin{array}{l}\text { Brambilla et al } .^{54} \\
\text { Garn et al } 1^{59} \\
\text { Himes et al }{ }^{61} \\
\text { Deurenberg et al }{ }^{64} \\
\text { Garn } \\
{ }^{60} \\
\text { Willett et al }{ }^{7} \\
\text { Malina et al }{ }^{57} \\
\text { Marshall et al }{ }^{65}\end{array}$ \\
\hline Elderly & $\begin{array}{l}\text { - Sarcopenia: muscular mass loss accompanied by an increase in adiposity } \\
\text { - Centripetal body fat distribution }\end{array}$ & $\begin{array}{l}\text { Seidell et al }{ }^{66} \\
\text { Willtet et } \mathrm{al}^{7} \text {; }\end{array}$ \\
\hline
\end{tabular}

and not the current body weights are considered, suggesting a potentially consistent clinical application.

Finally, it is possible that with the simple height and weight measures and consequent use of the reciprocal ponderal index or ectomorphy, the latter for those who work with so- matotyping, we will be able to detect overweight and obesity in childhood earlier. Better still, we may be able to relate data of children with those of their parents, using the same and single normal range. Further prospective studies are required to confirm or deny the validity of this attractive proposal.

\section{References}

1. Sinclair D. Human Growth after Birth. $3^{\text {rd }}$ ed. London: Oxford University Press, 1978

2. Ross WD, Carter JEL, Carr RV. Anthropometry Illustrated [CD-ROM]. Burnaby: Turnpike Electronic Publications, 2000.

3. Adams GM. Exercise Physiology - Laboratory Manual. $3^{\text {rd }}$ ed. New York: McGraw-Hill, 1999.

4. International Obesity Task Force. About Obesity. Available from: URL: http:// www.obesite.chaire.ulavl.ca/iotf.htm in 16/2/2001.

5. World Health Organization. Press release 46. Obesity epidemic puts millions at risk from related diseases. Available from: URL: http://www.who.int/archives/ int-pr-1997//en/pr9/-46.html in 16/2/2001.

6. Wang JX, Davies M, Norman RJ. Body mass and probability of pregnancy during assisted reproduction treatment: retrospective study. Br Med J 2000;321: 1321-2.

7. Willett WC, Dietz WH, Colditz GA. Guidelines for healthy weight. N Engl J Med 1999;341:427-34.

8. Bundred P, Kitchiner D, Buchan I. Prevalence of overweight and obesity children between 1989 and 1998: population based series of cross sectional studies. BrMed J 2001;322: 1-4.

9. Chinn S, Rona RJ. Prevalence and trends in overweight and obesity in three cross sectional studies of British children, 1974-94. BrMed J 2001; 322: 24-6.

10. Cole TJ, Bellizzi MC, Flegal KM, Dietz WH. Establishing a standard definition for child overweight and obesity worldwide: international survey. Br Med J 2000;320: 1240-3.

11. Center for Disease Control and Prevention. Body mass index-for-age: BMI is used differently with children than it is with adults. Available from: URL: http:/ www.cdc.gov/nccdphp/dnpa/bmi/bmi-for-age.htm in 25/9/2000.

12. Fregal KM, Carroll MD, Kuczmarski RJ, Johnson CL. Overweight and obesity in United States: prevalence and trends, 1960-1994. Int J Obes Metab Disord 1998; $22: 39-47$

13. Instítuto Brasileiro Geografia e Estatística. Pesquisa de padrão de vida(PPV). Disponível em URL: http:/www.ibge.gov.br/imprensa/noticias/ppv11.htm in 26/8/1998.

14. National Task Force on the Prevention and Treatment of Obesity. Overweight, obesity, and health risk. Arch Intern Med 2000; 160: 898-904.

15. Wei M, Kampert JB, Barlow CE, et al. Relationship between low cardiorespirato- ry fitness and mortality in normal-weight, overweight, and obese men. JAMA $1999 ; 282: 1547-53$

16. Eckel RH, Krauss RM. American Heart Association call to action: obesity as a major risk factor for coronary heart disease. Circulation 1998; 97: 2099-100.

17. Krauss RM, Eckel RH, Howard BV, et al. Revision 2000: a statement for healthcare professionals from the Nutrition Committee of the American Heart Association. Circulation 2000; 102: 2284-99.

18. Kries RV, Koletzko B, Sauerwald T, et al. Breast feeding and obesity: cross-sectional study. Br Med J 1999; 319: 147-50.

19. Grundy SM, Benjamin IJ, Burke GL, et al. Diabetes and cardiovascular disease: a statement for healthcare professionals from the American Heart Association. Circulation 1999; 100: 1134-46.

20. EckelRH. Obesity and heart disease: a statement forhealthcare professional from the nutrition committee, American Heart Association. Circulation 1997; 96 : 3248-50.

21. Redline S, Tishler PV, Schluchter M, Aylor J, Clark K, Graham G. Risk factors for sleep-disordered breathing in children. Association with obesity, race, and respiratory problems. Am J Respir Crit Care Med 1999; 159: 1527-32.

22. Pi-Sunyer FX. Medical hazards of obesity. Ann Intern Med 1993; 119: 655-60

23. Hall IJ, Newman B, Millikan RC, Moorman PG. Body size and breast cancer risk black womaen and white women: the Carolina Breast Cancer Study. Am J Epidemiol 2000; 151:754-64.

24. Huang Z, Hankinson SE, Colditz GA, et al. Dual effects of weight and weight gain on breast cancer risk. JAMA 1997; 278: 1407-11.

25. Giovannucci E, Colditz GA, Stampfer MJ, Willett WC. Physical activity, obesity, and risk of colorectal adenoma in women. Cancer Causes Control 1996 7:253-63.

26. Ballard-Barbash R, Swanson CA. Body weight: estimation of risk for breast and endometrial cancers. Am J Clin Nutr 1996; 63(suppl 3): S437-41.

27. Lee IM, Paffenbarger RS Jr. Quetelet's index and risk of colon cancer in college alumni. J Natl Cancer Inst 1992; 84: 1326-31.

28. Garfinkel l. Overweight and cancer. Ann Intern Med 1985; 103: 1034-6.

29. Hanley AJG, Harris SB, Gittelsohn J, Wolever TMS, Saksvig B, Zinman B. Overweight among children and adolescents in a Native Canadian community: prevalence and associated factors. Am J Clin Nutr 2000; 71: 693-700. 
30. Mokdad AH, Serdula MK, Dietz WH, Bowman BA, Marks JS, Koplan JP. The spread of the obesity epidemic in the United States. JAMA 1999; 282: 1519-22.

31. Eriksson JG, Forsén T, Tuomilehto J, Winter PD, Osmond C, Barker DJP. Catchup growth in childhood and death from coronary heart disease: longitudinal study. BrMed J 1999; 318: 427-31.

32. Lean MEJ, Han TS, Seidell JC. Impairment of health and quality of life using new US Federal Guidelines for the identification of obesity. Arch Intern Med 1999; 159:837-43.

33. Gallagher D, Heymsfield SB, Heo M, Jebb SA, Murgatroyd PR, Sakamoto Y. Healthy percentage body fat ranges: an approach for developing guidelines based on body mass index. Am J Clin Nutr 2000; 72: 694-701.

34. Bellizzi MC, Dietz W. Workshop on childhood obesity: summary of the discussion. Am J Clin Nutr 1999; 70: S173-5.

35. Mo-Suwan L, Pongprapai S, Junjana C, Puetpaiboon A. Effects of a controlled trial of a school-based exercise program on the obesity indexes of preschool children. Am J Clin Nutr 1998; 68: 1006-11.

36. Moore LL, Nguyen UDT, Rothman KJ, Cupples LA, Ellison RC. Preschool physical activity level and change in body fatness in young children. Am J Epidemiol 1995; 142: 982-8

37. Oliveira F. Magras e poderosas. Revista Veja, 2001; Jan 10: 1682

38. Rubinstein S, Caballero B. Is Miss America an undernourished role model JAMA 2000; 283: 1569.

39. Smalley KJ, Knerr NA, KendrickZV, Colliver JA, Owen OE. Reassessment of body mass indices. Am J Clin Nutr 1990; 52: 405-8.

40. Ross WD, Drinkwater DT, Bailey DA, Marshall GR, Leahy RM. Kinanthropometry: traditions and new perspectives. In: Ostyn M, Beunen G, Simons J, editors. Kinanthropometry II. Baltimore: University Park Press; 1980: 3-26.

41. Heath BH, Carter JEL. A comparison of somatotype methods. Am JPhys Anthropol 1966; 24: 87-100.

42. Heath BH, Carter JEL. A modified somatotype method. Am J Phys Anthropol 1967;27:57-74.

43. Araújo CGS. Fundamentos Biológicos/Medicina Desportiva: Rio de Janeiro: Ao Livro Técnico, 1985

44. Ricardo DR, Araújo CGS. Teste de sentar-levantar: influência do excesso de peso corporal em adultos. Rev Bras Med Esporte 2001; 7: 45-52.

45. Marcondes E, Gonzalez CH, Machado DVM,D'Agostino G,Zuccolotto M, Setian N. Crescimento normal e deficiente. $2^{\text {nd }}$ ed. SãoPaulo: Sarvier, 1978.

46. Geigy Scientific Tables 3: physical chemistry, composition of blood, hematology, and somatometric data. New Jersey: Ciba Geigy, 1984.

47. Araújo DSM, Chaves CPG, Ricardo DR, Oliveira EG, Nizzo W, Araújo CGS Peso corporal em universitários: autopercepção e satisfação. IN: Anais do XII Simpósio Internacional de Ciências do Esporte: 5 a 8 de outubro de 2000: São Paulo, Brasil. São Paulo: Celafiscs, 2000: 80

48. Guo SS, Chumlea WC. Tracking of body mass in children in relation to overweight in adulthood. Am J Clin Nutr 1999; 70(suppl): S145-8.
49. Dietz WH. Therapeutic strategies in childhood obesity. Horm Res 1993; 39 (supp13): 86-90.

50. Gunnell DJ, Frankel SJ, Nanchahal K, Peters TJ, Smith GD. Childhood obesity and adult cardiovascular mortality: a 57-y follow-up study based on the Boyd Orr cohort. Am J Clin Nutr 1998; 67: S1111-8.

51. Guillaume M. Defining obesity in childhood: current practice. Am J Clin Nutr 1999; 70: S126-30

52. Sardinha LB, Going SB, Teixeira P, Lohman T. Receiver operating characteristic analysis of body mass index, triceps skinfold thickness, and arm girth for obesity screening in children and adolescents. Am J Clin Nutr 1999; 70: 1090-5.

53. Poskitt EME. Defining childhood obesity: the relative body mass index (BMI). ActPaediatric 1995;84:961-3.

54. Brambilla P. Body mass index in patients with unusual proportions [letter to editor] Am J Clin Nutr 1997; 66: 1295.

55. Michielutte R, Diseker RA, Corbett WT, Schey HM, Ureda JR. The relationship between weight-height indices and the triceps skinfold measure among children age 5 to 12. Public Health Briefs 1984; 74: 604-6.

56. Micozzi MS, Albanes D, Jones DY, Chumlea WC. Correlation of body mass indices with weight, stature, and body composition in men and women in NHANES I and II. Am J Clin Nutr 1986; 44: 725-31.

57. Malina RM, Katzmarzk PT. Validity of the body mass index as an indicator of the risk and presence of overweight in adolescents. Am J Clin Nutr 1999; 70: S131-6.

58. Lee J, Kolonel LN, Hinds MW. Relative merits of weight-corrected-for-height indices. Am J Clin Nutr 1981; 34: 2521-9.

59. Garn SM, Leonard WR, Hawthorne VM. Three limitations of the body mass index[letter]. Am J Clin Nutr 1986; 44:996-7.

60. Garn SM. Body mass index in patients with unusual proportions[letter to editor]. Am J Clin Nutr 1997; 66: 1294.

61. Franklin MF. Comparison of weight and height relations in boys from 4 countries. Am J Clin Nutr 1999; 70(suppl): S157-62.

62. Himes JH, Dietz WH. Guidelines for overweight in adolescent preventive services: recommendations from an expert committee. Am J Clin Nutr 1994; 59:307-16.

63. Daniels SR, Khoury PR, Morrison JA. The utility of body mass index as a measure of a measure of body fatness in children and adolescents: diferences by race and gender. Pedistrics 1997; 99;804-7.

64. Deurenberg P, Deurenberg YM, Wang J, Lin FP, Schimidt G. The impact of body build on the relationship between body mass index and percent body fat. Int J Obes Relat Metab Disord 1999; 23: 537-42.

65. Marshall D, HazlettCB, Spady DW, Conger PR, Quinney HA. Validity of convenient indicators of obesity. Hum Biol 1991; 63: 137-53

66. Seidell JC, Hautvast JG, Deurenberg P. Overweight: fat distribution and health risks. Epidemiological observations. A Review. Infusionstherapie 1989; 16: 276-81 